\title{
Programlanabilir lojik kontrolör (PLC) tarafından yönetilen bir tartılı lizimetre sisteminin geliştirilmesi
}

\section{Development of a weighting lysimeter system operated by a programmable logic controller (PLC)}

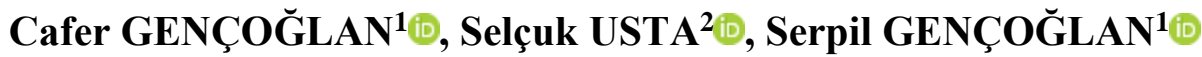

${ }^{1}$ Kahramanmaraş Sütçü İmam Üniversitesi, Ziraat Fakültesi, Biyosistem Mühendisliği Bölümü, 46040, Kahramanmaraş

${ }^{2}$ Van Yüzüncü Y1l Üniversitesi, Van Meslek Yüksekokulu, İnşaat Bölümü, 65090, Van

Sorumlu yazar (Corresponding author): S. Usta, e-posta (e-mail): susta@yyu.edu.tr

Yazar(lar) e-posta (Author e-mail): gencoglan@ksu.edu.tr, sgencoglan@ksu.edu.tr

MAKALE BİLGİSİ

Alınıs tarihi 30 Aralık 2019

Düzeltilme tarihi 28 Ocak 2020

Kabul tarihi 05 Şubat 2020

\section{Anahtar Kelimeler:}

CODESYS

Evapotranspirasyon

PLC

Tartılı lizimetre

\section{öz}

Bu çalıșmada; PLC tarafından kontrol edilebilen bir tartılı lizimetre sistemi geliștirilerek, Kahramanmaraş koşullarında Maraş 18 tipi ceviz bitkisi üzerinde test edilmesi amaçlanmıştır. $\mathrm{Bu}$ amaç doğrultusunda, öncelikle $3 \mathrm{~mm}$ kalınlıklı paslanmaz çelik sac kullanılarak bir lizimetre tankı oluşturulmuştur. Lizimetre tankı $113 \mathrm{~cm}$ çapında ve $130 \mathrm{~cm}$ derinliğinde olup, $1.5 \times 1.5 \mathrm{~m}$ boyutlarındaki bir elektronik kantarın üzerine yerleştirilmiştir. Kantar 5 ton kapasiteli olup, 4 adet yük algılayıcısına ve RS 232 çıkıșa sahiptir. Lizimetre tankına yağışla giren su miktarını ve drenaj yoluyla çıkan su miktarını ölçmek amacıyla iki adet plüviyometre kullanılmıștır. Lizimetre tankının altına Ø 25 çaplı bir çıkış koyularak, drenajla çıkan su aynı çaptaki bir boru ile plüviyometreye aktarılmıștır. Günlük evapotranspirasyon miktarının belirlenmesinde su bütçesi eşitliği kullanılmıştır. Sulama sistemi, kantar ve plüviyometreler PLC tarafindan kontrol edilmiștir. Bu doğrultuda CODESYS programlama dili kullanılarak lizimetre, yağış ölçümü, drenaj ölçümü ve sulama programları hazırlanmış ve PLC'ye yüklenmiștir. Lizimetre sistemi kullanılarak; ceviz bitkisinin 2018 yll Haziran-Ekim dönemi boyunca toplam evapotranspirasyon miktarının $261 \mathrm{~mm}$ olduğu, günlük evapotranspirasyon miktarının ise 1.25-3.5 mm gün ${ }^{-1}$ arasında değiştiği belirlenmiştir.

\section{ARTICLE INFO}

Received 30 December 2019

Received in revised form 28 January 2020

Accepted 05 February 2020

\section{Keywords:}

CODESYS

Evapotranspiration

PLC

Weighting lysimeter

\section{ABSTRACT}

In this study; it is aimed to develop a weighting lysimeter system that can be controlled by PLC and tested on Maras 18 type walnut crop in Kahramanmaras conditions. For this purpose, a lysimeter tank was formed using $3 \mathrm{~mm}$ thick stainless steel sheet. The lysimeter tank has a diameter of $113 \mathrm{~cm}$ and a deep of $130 \mathrm{~cm}$ and was placed on an electronic weighbridge that $1.5 \times 1.5 \mathrm{~m}$ surface dimensions. The weighbridge has 5 tons capacity, 4 load sensors and RS 232 output. Two pluviometers were used to measure the amount of water entering the lysimeter tank by precipitation and the amount of water exiting of the tank through drainage. An outlet with a diameter of $\varnothing 25$ was placed under the lysimeter tank and the water exiting of the drainage was transferred to the pluviometer by a pipe of the same diameter. Water budget equality was used to determine the amount of daily evapotranspiration. Weighbridge, pluviometers and irrigation system were controlled by PLC. In this direction, lysimeter, precipitation measurement, drainage measurement and irrigation programs have been prepared by using CODESYS programming language and loaded to PLC. With weighting lysimeter system; the total amount of evapotranspiration of walnut crop was determined $261 \mathrm{~mm}$ and the amount of daily evapotranspiration between 1.25-3.5 mm day ${ }^{-1}$ during the June-October period of 2018 . 


\section{Giriş}

Bitki-toprak sistemine sulama ve yağışla giren su sırasıyla yüzey akış, derine sızma, toprak yüzeyinden buharlaşma (Evaporasyon) ve bitki yüzeyinden terleme (Transpirasyon) ile kayıplara uğramaktadır. Buharlaşma ve terleme kayıplarının toplamı bitki su tüketimi (Evapotranspirasyon-ET c $_{\mathrm{c}}$ olarak adlandırılmaktadır. $\mathrm{ET}_{\mathrm{c}}$ bitki, toprak ve iklim özelliklerine bağ $l_{1}$ çok sayıda etmenin etkisiyle gerçekleştiğinden dolayı doğadaki en karmaşık olaylardan birisi olarak kabul edilmektedir (Kanber 2006). $\mathrm{ET}_{\mathrm{c}}$ lizimetre sistemleri ile doğrudan ölçülebildiği gibi bitki, toprak ve iklim özelliklerine bağlı olarak geliştirilen çeşitli ampirik yöntemler ile tahmin edilebilmektedir.

Sulama sistemlerinin projelendirilmesinde dikkate alınan temel veri, bu sistemlerin kurulacağ bitkilerin $\mathrm{ET}_{\mathrm{c}}$ miktarlarıdır. Bu miktarların tahmin edilmesinde kullanılan ampirik yöntemlerin güvenilirlikleri, yöreden yöreye hatta aynı yörede yetiştirilen çeşitli bitkiler için farklılıklar gösterebilmektedir. Yöre ve arazi koşullarına uygun olarak oluşturulan ve işletilen lizimetre sistemleri ile gerçeğe en yakın $E_{c}$ miktarları elde edilebilmektedir (Doorenbos ve Pruitt 1977).

Bitki-toprak sistemine yağış ve sulama ile giren, drenaj ve evapotranspirasyon ile çıkan su miktarlarını belirlemek amaciyla, bitki-toprak sisteminin bir bölümü çevresinden izole edilerek sisteme giren ve çıkan su miktarları ölçülebilmektedir. $\mathrm{Bu}$ amaçla oluşturulan düzeneklere lizimetre adı verilmektedir. Lizimetre tankı içerisindeki bitki-toprak sistemine yağış ve sulama suyu ile giren su miktarları ve drenajla çıkan su miktarı ölçüldükten sonra, bir boyutlu su bütçesi eşitliği kullanılarak evapotranspirasyon $\left(\mathrm{ET}_{\mathrm{c}}\right)$ miktarı belirlenebilmektedir (Aydınşakir ve Büyüktaş 2014).

Lizimetre sistemleri, tartılan ve tartılamayan olmak üzere iki gruba ayrılmaktadır. Tartılı lizimetre sistemlerinde, lizimetre tankı ikinci ve daha büyük bir tankın içerisine yerleştirilerek, tartım için serbestçe hareket etmesi sağlanmaktadır. Belirli zaman aralıklarıyla ölçülen lizimetre tankı ağırlıkları arasındaki farklar, toprak suyu içeriğindeki değişimi yani evapotranspirasyon ( $\left(\mathrm{ET}_{\mathrm{c}}\right)$ miktarını büyük bir doğrulukla vermektedir. Ancak, evapotranspirasyon miktarlarının yağış, sulama ve drenaj miktarları göz önünde bulundurularak bir boyutlu su dengesi eşitliği ile kontrol edilmesi gerekmektedir. Tartılamayan lizimetre sistemleri, toprak içerisine yerleştirilen su geçirmez madeni veya beton havuzlar şeklinde oluşturulmaktadır. Bu lizimetre tipinde toprak suyu içeriğindeki değişim direkt olarak ölçülememektedir. Gravimetrik örnekleme, matrik potansiyelin ölçümü, elektriksel direnç ve nötron saçılma yöntemlerinden birisi kullanılarak toprak suyu içeriğindeki değişimin belirlenmesi gerektiğinden dolayı, bu tip lizimetreler evapotranspirasyon miktarının belirlenmesinde çok fazla tercih edilmemektedirler (Aboukhaled ve ark. 1982; Gençoğlan ve ark. 2019).

Tartılı lizimetre sistemleri daha çok evapotranspirasyon miktarının ölçülmesi ve yağış etkinliğinin belirlenmesi amacıyla kullanılmaktadır. Ayrıca evapotranspirasyon miktarının tahmin edilmesinde kullanılan ampirik yöntemlerin yöre ve arazi koşullarına uygun olarak kalibrasyonlarının yapılmasında tartılı lizimetre sistemlerinden faydalanılmaktadır. Aboukhaled ve ark. (1982), Aydınşakir ve ark. (2003), Benli ve ark. (2006), Ünlü ve ark. (2010), Akpolat (2011), Nur (2019) ve Yıldız (2019) farklı bitki, iklim ve arazi koşullarında $\mathrm{ET}_{\mathrm{c}}$ miktarlarını belirlemek, mikrometeorolojik yöntemler ve lizimetre sistemleri ile belirlenen $\mathrm{ET}_{\mathrm{c}}$ miktarlarını karşılaştırmak ve $\mathrm{ET}_{\mathrm{c}}$ tahmininde kullanılan çeşitli ampirik yöntemleri kalibre etmek amacıyla yaptıkları çalışmalarda tartılı lizimetre sistemlerini kullanmışlardır. Bu çalışmaların çoğunda insan gücüne dayalı manuel tartılı lizimetre sistemleri kullanılmıştır. Bu tür lizimetre sistemlerinde yağış ve drenaj miktarlarının günlük olarak ölçülmesi, topraktaki su içeriği değişimine bağlı olarak saatlik ve günlük lizimetre tankı ağırlıklarının belirlenmesi ve ayrıca lizimetre tankındaki bitkiye belirli aralıklarla sulama suyunun verilmesi işlemleri ekstra zaman ve işgücü kullanımı gerektirmektedir. Belirtilen bu ölçme ve kontrol işlemlerinin yapılmasında otomasyon sistemleri kullanılarak, zaman ve iş gücünden tasarruf edilebilmekte ve ölçme işlemlerinin hassasiyeti artırılabilmektedir. $\mathrm{Bu}$ nedenlerden dolayı, yerli imkânlar kullanılarak otomasyon kontrollü tartılı lizimetre sistemlerinin geliştirilmesine ve kullanımlarının yaygınlaştırılmasına ihtiyaç duyulmaktadır.

$\mathrm{Bu}$ çalışmada; günlük yağış ve drenaj miktarlarını plüviyometrelere, lizimetre ağırlıklarını ise elektronik kantara ölçtürerek kaydeden; bu verileri kullanarak lizimetre tankında bulunan Maraş 18 tipi ceviz bitkisinin günlük evapotranspirasyon miktarlarını ve sulama suyu ihtiyacını hesaplayan ve kaydeden; sulama zamanını belirleyerek sulamayı otomatik olarak başlatan ve suyun tamamı bitkiye verildiğinde otomatik olarak bitiren; PLC tabanlı otomasyon sistemi tarafindan kontrol edilen bir tartılı lizimetre sisteminin geliştirilmesi amaçlanmıştır.

\section{Materyal ve Yöntem}

$\mathrm{Bu}$ çalışma, Kahramanmaraş Sütçü İmam Üniversitesi Ziraat Fakültesi Uygulama Bahçelerinde oluşturulan deneme alanında, 2018 yılının Haziran-Ekim dönemi boyunca yürütülmüştür. Çalışma kapsamında öncelikli olarak tartılı lizimetre tank1, elektronik kantar, plüviyometreler, damla sulama sistemi ve kontrol panosu kisımlarının bir araya getirilmesi ile Şekil 1'de verilen PLC kontrollü tartılı lizimetre sistemi oluşturulmuştur. Tartılı lizimetre tankı $3 \mathrm{~mm}$ kalınlığa sahip paslanmaz çelik saçtan imal edilmiştir. Toprak yüzeyi alanının $1 \mathrm{~m}^{2}$ olabilmesi için çap1 $113 \mathrm{~cm}$ ve ceviz bitkisinin ortalama etkili kök derinliği dikkate alınarak derinliği $130 \mathrm{~cm}$ olarak tasarlanmıştır. Tartılı lizimetre sistemi toprak dışında tesis edildiğinden dolayı, çevresi cam yünü ile kaplanarak hava akımı ve güneş enerjisinin etkisi azaltılmıştır.

Lizimetre tank1, $1.5 \times 1.5 \mathrm{~m}$ yüzey boyutlarında, $\pm 200 \mathrm{~g}$ hassasiyetle ölçüm yapabilen, 5 ton kapasiteli, 4 adet yük algılayıcısına (load cell) ve dönüştürücü karta sahip RS 232 çıkışlı bir elektronik kantarın üzerine oturtulmuştur. Kantar, bir su düzeci aracılığı ile tesviye edilmiştir. Lizimetre tankından drenajla süzülen su miktarını ölçmek için devrilen kovalı plüviyometre kullanılmıştır. Tankın altına Ø 25 çıkış verilerek, bir boru ile plüviyometreye bağlanmıştır. Drenajla süzülen su miktarını ölçen plüviyometrenin üzeri kapatılarak, yağışla su girişi önlemiştir. Yağışı ölçmek için başka bir devrilen kovalı plüviyometre kullanılmıştır. Plüviyometrelerin ağız çapları 160 $\mathrm{mm}$, yüzey alanları $20096 \mathrm{~mm}^{2}$ ve kova hacimleri $4448 \mathrm{~mm}^{3}$ olarak belirlenmiştir.

Yağış ve sulama suyu ile tanka giren suyun drenajını kolaylaştırmak amacıyla, tankın en alt kısmına $10 \mathrm{~cm}$ yüksekliğinde çakıl serilmiştir. Çakılın üzerine paslanmaz krom nikel kaplı $0.5 \mathrm{~cm}$ gözenekli elek filtre yerleştirilerek, geriye kalan $120 \mathrm{~cm}$ yüksekliğindeki kısım toprakla doldurulmuş ve Maraş 18 tipi ceviz fidanı dikilmiştir. Tartılı lizimetre tankına doldurulacak toprağı temin etmek amaciyla, sistemin kurulduğu 


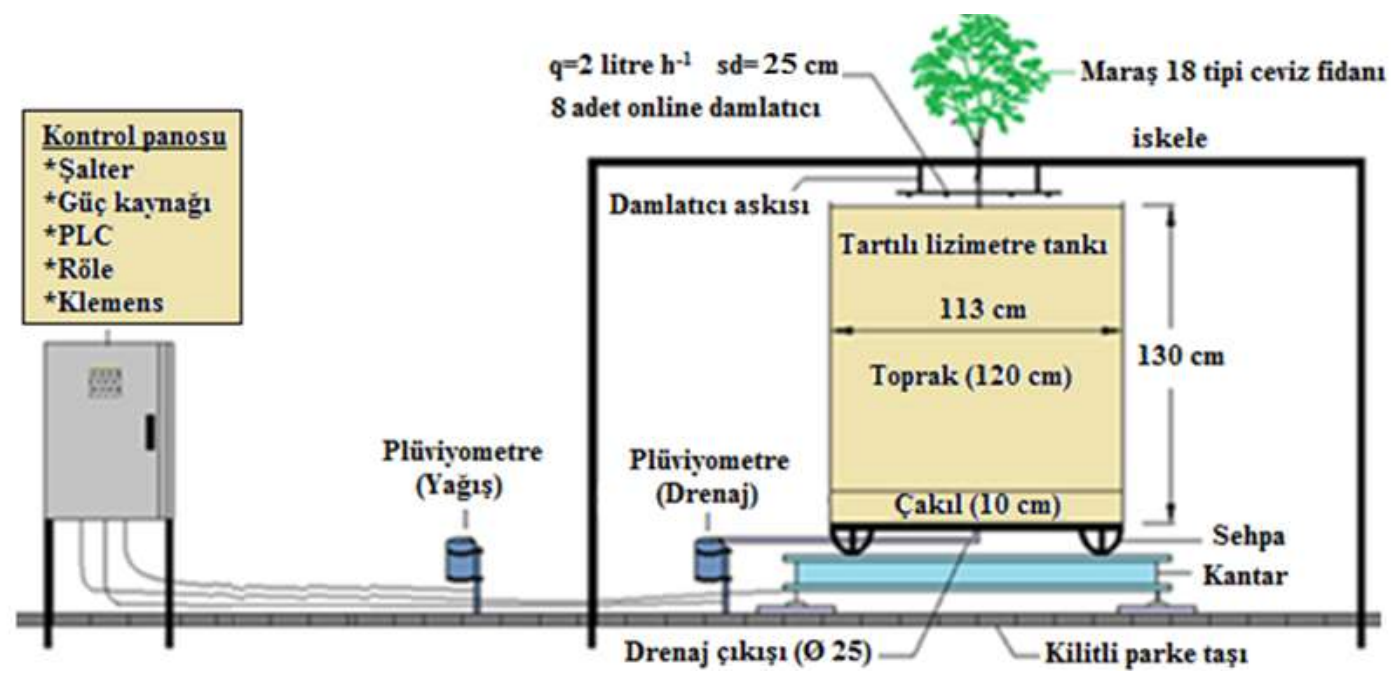

Şekil 1. PLC kontrollü tartılı lizimetre sistemi.

Figure 1. PLC controlled weighting lysimeter system.

alana yakın bir yerde, $1 \mathrm{~m}^{2}$ yüzey alanı altında $120 \mathrm{~cm}$ derinliğindeki toprak profili $10 \mathrm{~cm}$ yüksekliğinde tabakalar halinde kazılarak etiketli torbalara doldurulmuştur. Alınan bu topraklar aynı katman sırasına göre, sıkıştırılarak lizimetre tankına doldurulmuştur.

Tartılı lizimetre tankına dikilen ceviz bitkisinin sulanmasında şebeke suyu kullanılmıştır. $\varnothing 32$ çaplı PE boru ile şebekeden alınan sulama suyu sırasıyla küresel vana, solenoid vana ve dijital su sayacından geçirilerek, $\varnothing 20$ çaplı kangal boru ile oluşturulan damla sulama sistemi aracillğ 1 ile lizimetre tankındaki ceviz bitkisine verilmiștir. Damlatıcı debileri $2 \mathrm{l} \mathrm{h}^{-1}$ olan sekiz adet online damlatıc1 $25 \mathrm{~cm}$ ara mesafe ile dairesel olarak ceviz bitkisinin etrafina yerleştirilmiştir. Sulama sistemi bir iskele vasıtasıyla lizimetre tankındaki cevize ulaştırılmıştır.

Selenoid vana paslanmaz çelikten imal edilmiş olup, 0.5 inç çaplı ve BSP dişi bağlantılıdır. Debi faktörü $\left(\mathrm{K}_{v}\right) 3.9 \mathrm{~m}^{3} \mathrm{~h}^{-1}$, maksimum çalışma basıncı 10 bar ve çalışma sıcaklığ $1-10^{\circ} \mathrm{C}$ ile $+100^{\circ} \mathrm{C}$ aralığındadır. Dijital su sayacı reed sensor okumalı olup, minimum debisi $0.025 \mathrm{~m}^{3} \mathrm{~h}^{-1}$, aşırı yük debisi 3.125 $\mathrm{m}^{3} \mathrm{~h}^{-1}$, geçiş akışı hız debisi $0.04 \mathrm{~m}^{3} \mathrm{~h}^{-1}$, ilk akış hız debisi $0.005 \mathrm{~m}^{3} \mathrm{~h}^{-1}$, kalıcı akış hız debisi $2.5 \mathrm{~m}^{3} \mathrm{~h}^{-1}$, maksimum çalışma sicaklığ $50^{\circ} \mathrm{C}$, nominal çap1 0.5 inç, maksimum çalışma basıncı 16 bar'dır. Su sayacının girişine 24 VDC gerilim uygulanarak, çıkışından 24 VDC gerilim alınmıştır.

Tartılı lizimetre otomasyon sisteminde merkezi işlem birimi (CPU) olarak PLC cihazı kullanılmıştır. PLC; çeşitli amaçlar doğrultusunda CODESYS dilinde hazırlanan programların yüklendiği, çeșitli cihaz ve sistemlerin kontrol edilmesini sağlayan bir otomasyon cihazıdır. Bu çalışmada kullanılan PLC; $128 \mathrm{~KB}$ program hafizasına, ethernet modülüne, hızlı sayıcı modüle, sinyal genişlik modülüne (PWM), 8 dijital girişe (DI), 6 dijital çıkışa (DO), 2 anaolog girișe (AI), 1 analog çıkışa (AO), gerçek zamanlı saat (RTC) ve SD modüle sahiptir. Girişi 24 VDC ve çıkışı 0.5 A olup, 4-20 mA arasında değişen akıma karşılık 1-27648 arasında sayısal değerler üretmektedir. Dış ortam çalışma sıcaklığı $0-60^{\circ} \mathrm{C}$ aralığındadır (ABB 2017). Ölçüm sonuçları 2 GB hafizalı SD karta kaydedilmiștir. Otomasyon sistemi kontrol panosu; PLC (CPU.1), iki adet güç kaynağ 1 (1U1, 1U2), beş adet otomatik sigorta (1F0, 1F1,1F2, 1F3,1F4), bir adet röle (2R1), RS 232 çıkışlı elektronik kantar paneli ve üç adet klemens grubundan oluşturulmuştur. Pano ana girişi ve güç kaynakları projesi Şekil 2'de verilmiştir.
PLC'nin lizimetre sistemine yağış ve sulama ile giren su miktarlarını ve drenajla çıkan su miktarını ölçebilmesi; bu doğrultuda plüviyometre, elektronik kantar ve dijital su sayac1 okumalarını yapabilmesi; selenoid vanayı kontrol ederek sulamayı otomatik olarak başlatıp bitirebilmesi amacıyla bir kontrol projesi hazırlanmıştır. Şekil 3'de verilen bu projede, su sayacı ve plüviyometrelerin girişlerine sirasıyla X11, X13 ve X15 klemens bağlantıları üzerinden 24 VDC akım uygulanarak, bu uç elemanların çıkışları sırasıyla X12, X14 ve X16 klemens bağlantıları üzerinden PLC'nin DI0, DI1 ve DI2 girişlerine bağlanmıştır. Selenoid vananın kontrol edilmesinde 24 VDC gerilim ve 5 A akıma sahip ray tipi röle (2.R1) kullanılmıştır. PLC'nin NQ0 çıkışı rölenin A1 ucuna, ortak ucu (com) ise rölenin A2 ucuna bağlanmıştır. PLC ile elektronik kantarın haberleştirilmesinde D-9 pin konnektörü kullanılmıştır. Kantar RS 232 protokolü vasitasiyla COM1 portu üzerinden PLC'ye bağlanmıştır.

Tartılı lizimetre sisteminin kontrol panosu Şekil 2 ve Şekil 3'de verilen projeler doğrultusunda oluşturulduktan sonra CODESYS dilinde lizimetre, sulama, yağış, drenaj ve SD kart veri yazdırma programları hazırlanarak PLC'ye yüklenmiştir. Lizimetre programı ilk olarak bir günlük dönemin başındaki lizimetre ağırlığını (LZM_1) tartmıştır. Daha sonra bir günlük süre boyunca yağış $(\mathrm{P})$ ve sulama (I) ile lizimetreye giren su miktarlarını ve drenajla lizimetreden çıkan su miktarını $\left(D_{\mathrm{p}}\right)$ belirleyerek, bir günlük dönemin sonundaki lizimetre ağırlığını (LZM 2) tartmıștır. Program, bu değișkenleri Eşitlik 1 ile verilen bir boyutlu su dengesi eşitliğinde yerine yazarak milimetre cinsinden günlük evapotranspirasyon (gun_ET) miktarını belirlemiştir (Young ve ark. 1996). Bir günlük süre boyunca yağış gerçekleşmediyse, sulama yapılmadıysa ve drenajla su çıkışı olmadıysa bu değişkenler sıfır olarak kaydedilmiştir. Bir sulama döngüsü iki sulama arasındaki dönem olarak tanımlanmıştır. Lizimetre programı Eşitlik 2'yi kullanarak bir sulama döngüsünde gerçekleşen toplam evapotranspirasyon miktarın (t_ET) milimetre cinsinden belirlemiştir.

$$
\text { gun_ET=LZM_1 + P + I - D p }- \text { LZM_2 }
$$

$$
\text { t_ET }=\Sigma \text { gun_ET }
$$




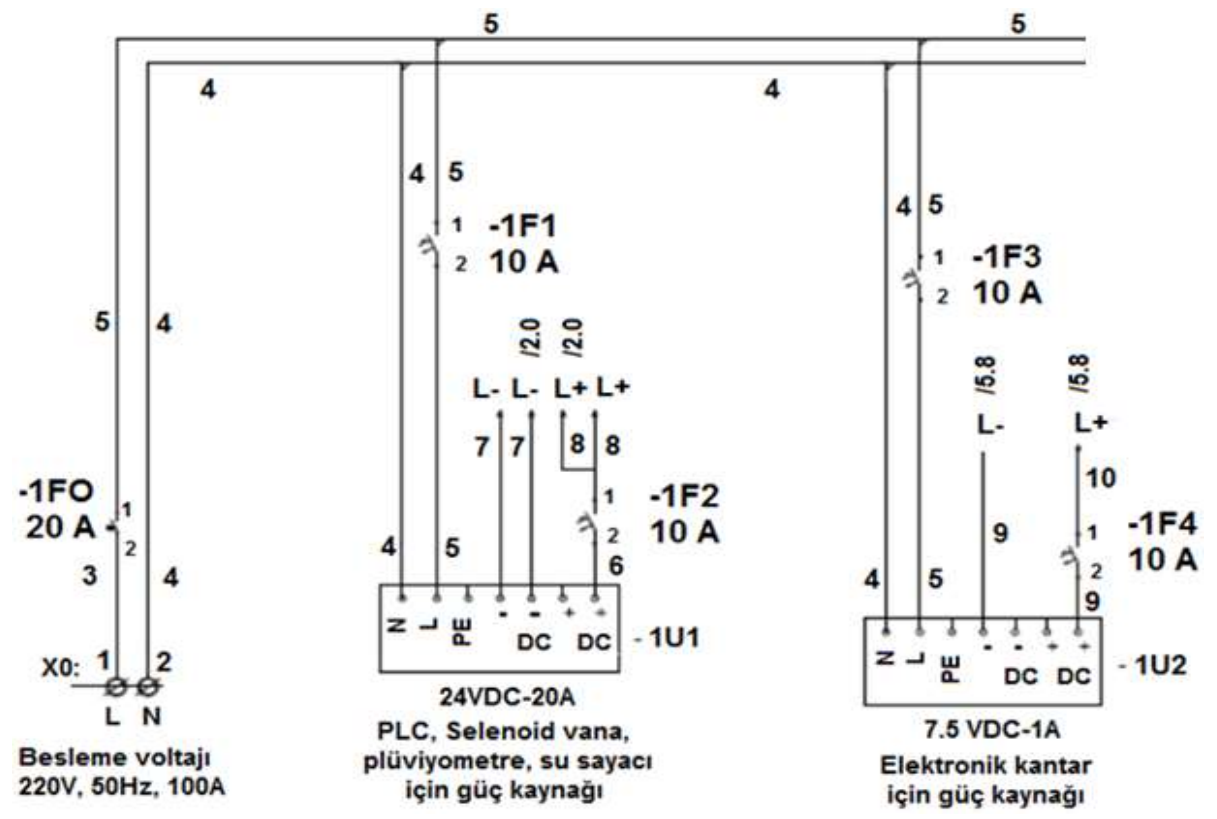

Şekil 2. Pano ana girişi ve güç kaynakları projesi.

Figure 2. Panel main entrance and power supplies project.

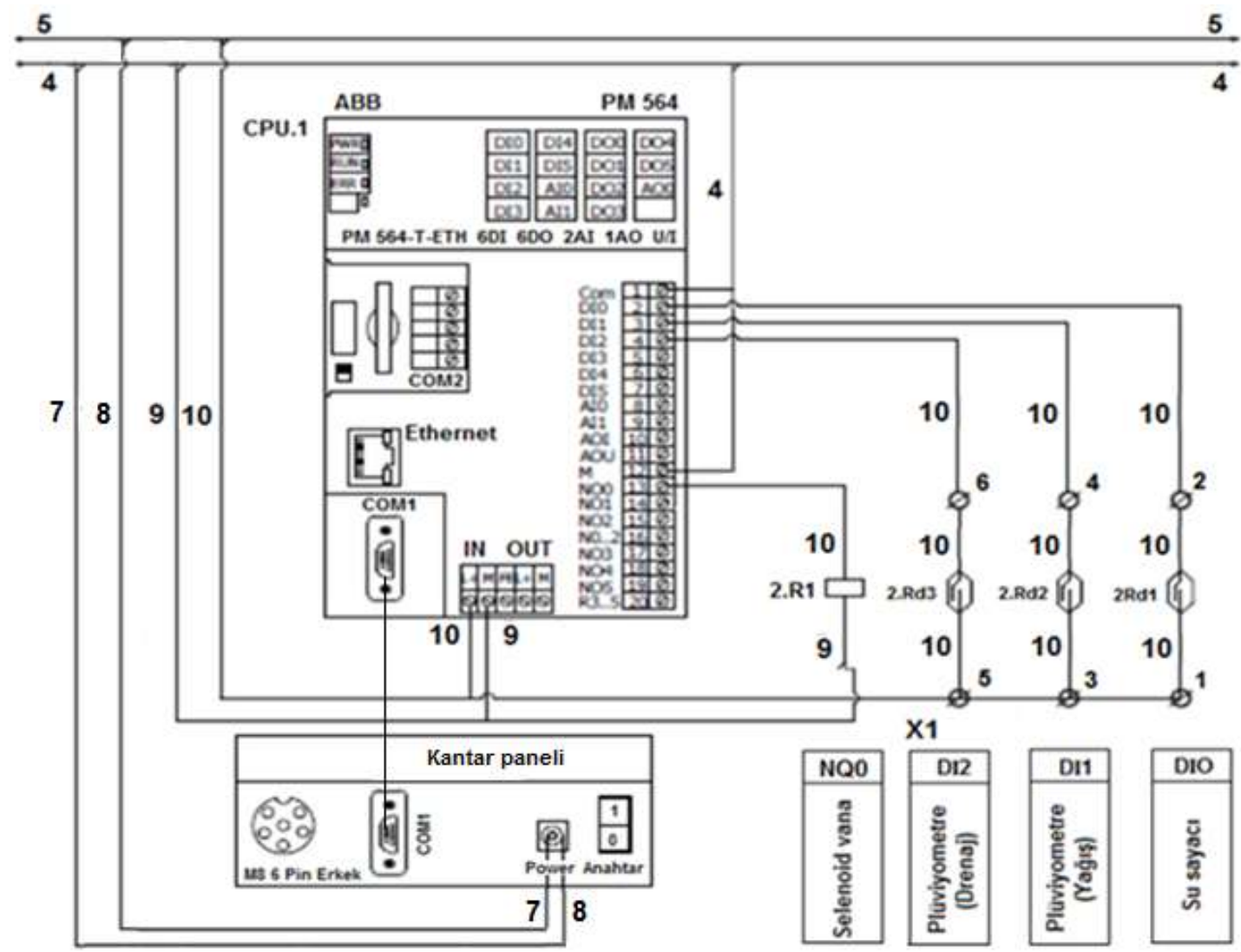

Şekil 3. Kantar, plüviyometreler, selenoid vana ve dijital su sayacı kontrol projesi.

Figure 3. Weighbridge, pluviometers, solenoid valve and water meter control project.

Sulama zamanı; bir sulama döngüsünde gerçekleşen t_ET miktarının 20 mm'ye eşit veya daha büyük olduğu gün olarak belirlenmişsir (t_ET $>=20 \mathrm{~mm}$ ). Bu miktarın belirlenmesinde güvenilir kaynaklardan elde edilen veriler kullanılmıştır. Bu doğrultuda ceviz bitkisinin ortalama günlük evapotranspirasyon miktarı 3-4 mm, ortalama sulama aralığı ise 4-5 gün kabul edilmiş ve bir sulama döngüsünde gerçekleşebilecek ortalama toplam su tüketimi $4 * 5=20 \mathrm{~mm}$ olarak belirlenmiştir (Hu ve ark. 2010; Akın 2016; TAGEM 2016). Bu değer, sulamay1 başlatan etmen (starter) olarak dikkate alınmıştır. Sıcaklığın 
yüksek olduğu günlerde cevizin su stresi yaşamaması için, bir sulama döngüsünde gerçekleşen t_ET miktarının \%120'si alınmış ve bu miktar sulama suyu (SSlm_mkt) olarak lizimetre tank1 toprak yüzeyi alanına (A) uygulanmıştır (Eşitlik 3). t_ET $>=20 \mathrm{~mm}$ olduğunda selenoid vana açılarak sulama başlatılmış ve su sayacından geçirilen su miktarı (su_say) sulama suyu miktarına (Slm_mkt) eşit olduğunda selenoid vana kapatılarak sulama bitirilmiştir.

$$
\text { Slm_mkt }=1.2 * t \_E T * A
$$

Günlük yağış ve drenajla süzülen su miktarlarını ölçmek amacıyla kullanılan plüviyometreleri kontrol etmek için yağış ve drenaj ölçümü programları hazırlanmıştır. Yağış ölçümü programı, yağışla dolup boşalan kova sayısını (yagis) kova hacmi (birim_hacim) ile çarpmış ve plüviyometre yüzey alanına (pluviyometre_alani) bölerek milimetre cinsinden günlük yağış (g_yagis) miktarını belirlemiştir (Eşitlik 4). Drenaj ölçümü programı, drenajla dolup boşalan kova sayısını (drenaj) kova hacmi (birim_hacim) ile çarpmış ve lizimetre tankı yüzey alanına (LZM_tank_alani) bölerek milimetre cinsinden günlük drenaj (g_drenaj) miktarını belirlemiş̧ir (Eşitlik 5).

$$
\begin{aligned}
& \text { g_yagis }=(\text { yagis }) *(\text { birim_hacim }) *(\text { pluviyometre_alani })^{-1} \\
& \text { g_drenaj }=(\text { drenaj }) *(\text { birim_hacim }) *(\text { LZM_tank_alani })^{-1}
\end{aligned}
$$

\section{Bulgular ve Tartışma}

Lizimetre tankı ağırlığını okuyan, plüviyometreler aracılığıyla günlük yağış (g_yagis) ve drenajla süzülen su miktarını (g_drenaj) ölçen, bu parametrelere bağlı olarak günlük evapotranspirasyon (gun_ET) ve bir sulama döngüsünde gerçekleşen toplam evapotranspirasyon (t_ET) miktarlarını belirleyen, t_ET $>=20 \mathrm{~mm}$ olduğunda sulama suyu miktarın (Slm_mkt) hesaplayarak sulamayı başlatan, bu doğrultuda selenoid vanayı, dijital su sayacını ve damla sulama sistemini kontrol eden, sulama suyunun tamamı bitkiye verildiğinde selenoid vanayı kapatarak sulamayı sonlandıran PLC kontrollü bir tartılı lizimetre sistemi geliştirilmiştir (Şekil 4).

Tartılı lizimetrenin kontrol edilmesini sağlayan otomasyon sistemi için Program Organizasyon Birimi (POU) altında bir PLC programı (PLC_PRG) oluşturulmuş ve bu programa ek olarak sırasıyla; Lizimetre [PRG], yagis_olc [PRG], drenaj_olc [PRG], Sulama [PRG], ve sd_kart_veri_yaz [PRG] programları hazırlanmıștır. SSekil 5'de verilen CODESYS arayüzü vasıtasıyla programlar birlikte çalıştırılmıştır.

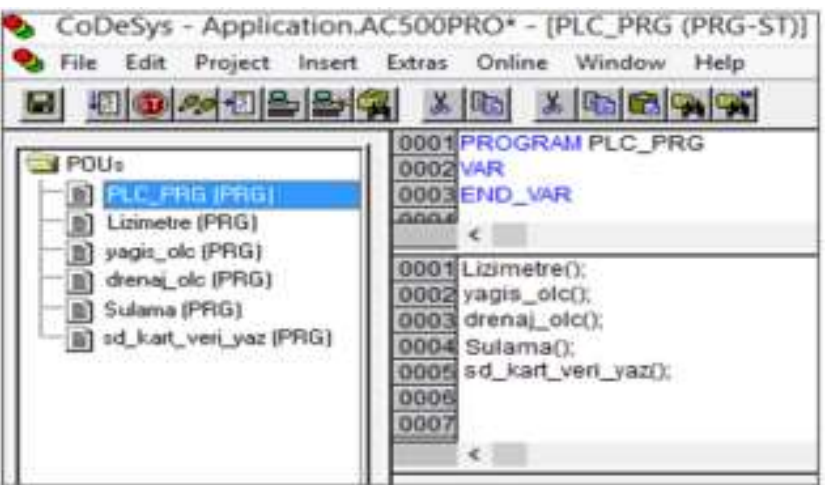

Şekil 5. Tartılı lizimetre otomasyonu programları ve CODESYS arayüzü.

Figure 5. Weighting lysimeter automation programs and CODESYS interface.

Tartılı lizimetre otomasyon sistemi için, ilk olarak akış diyagramı Şekil 6'da verilen Lizimetre [PRG] programı hazırlanmıştır. $\mathrm{Bu}$ programda öncelikle COM_REC fonksiyon bloğu kullanılarak kantardan lizimetre ağırlığı okunmuş ve "datarec" değişkenine atanmıştır. Daha sonra MID string fonksiyonu kullanılarak "datarec" değişkeni içerisinden lizimetrenin ağırlığı ayıklanmış ve "lzm" değişkenine atanmıştır.

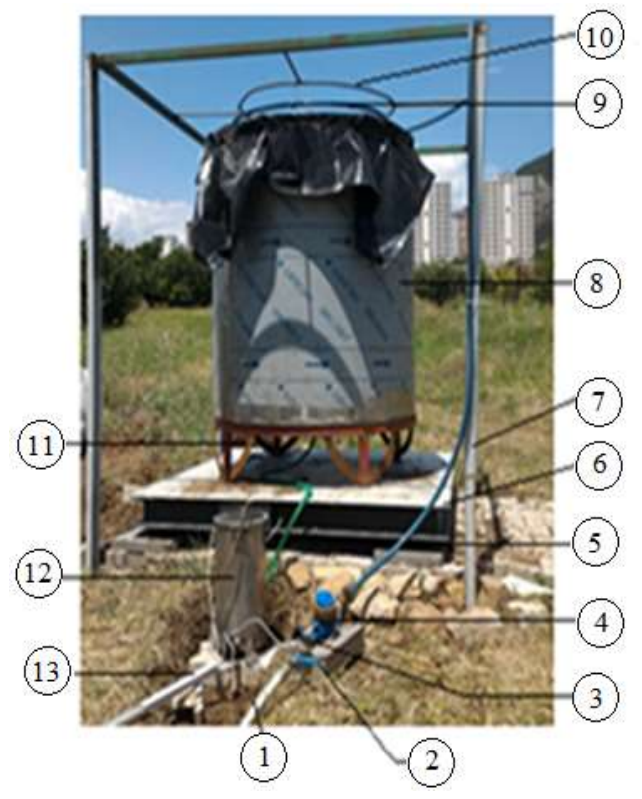

Şekil 4. Tartılı lizimetre sistemi.

Figure 4. Weighting lysimeter system.
1-) Ø $32 \mathrm{PE}$ boru
2-) Küresel vana
3-) Selenoid vana
4-) Dijital su sayac1
5-) Ø 20 kangal boru
6-) Kantar
7-) İskele
8-) Lizimetre tank1
9-) 8 Adet damlatic1
10-) Ask1
11-) Sehpa
12-) Plüviyometre
13-) PLC kablo kanal1

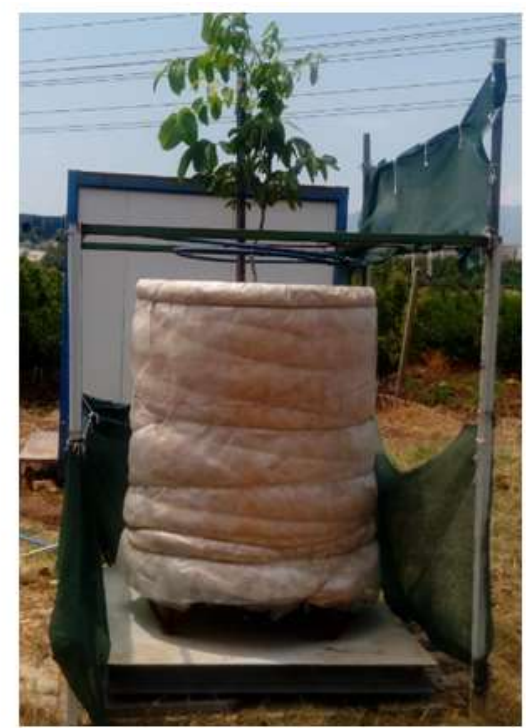




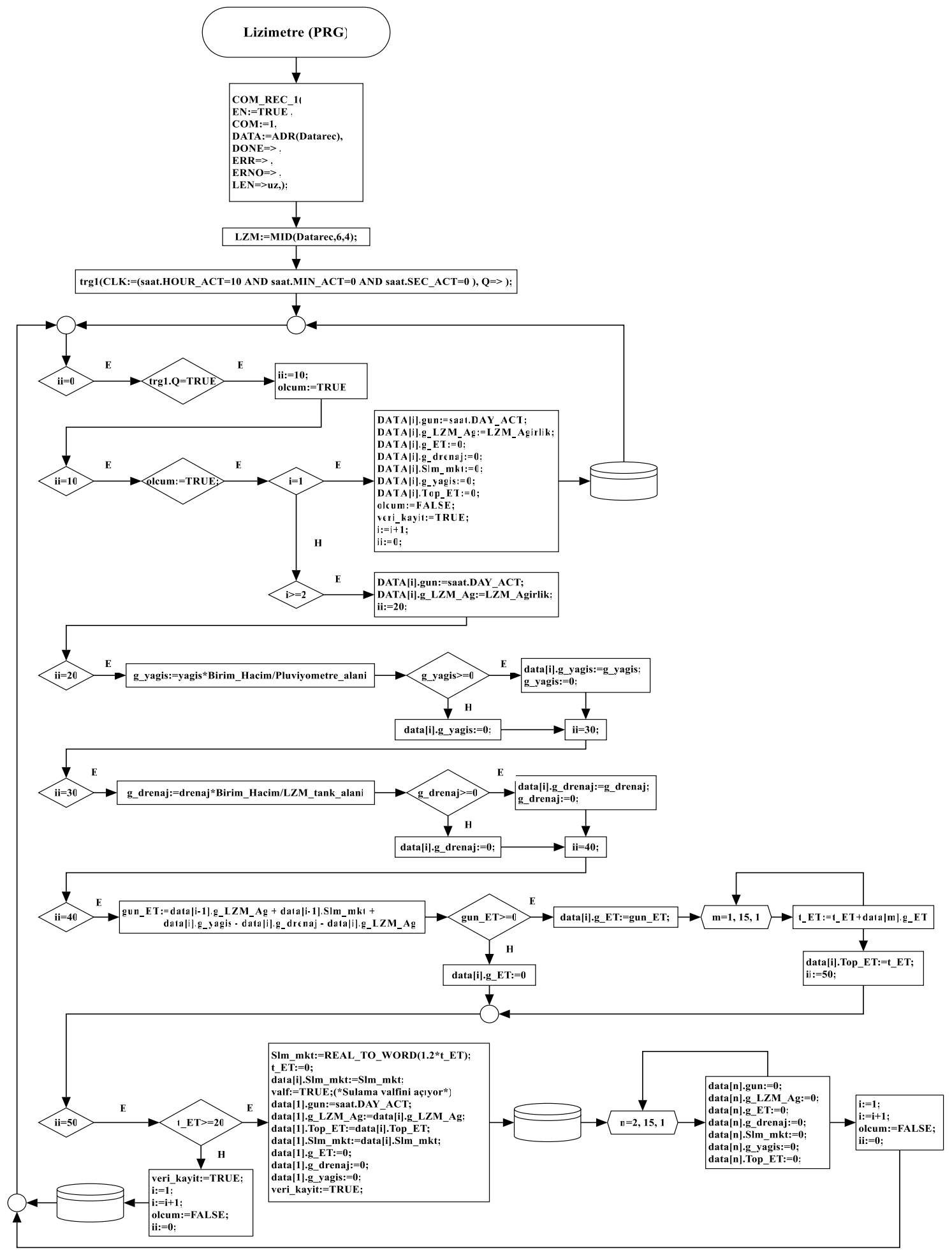

Şekil 6. Lizimetre [PRG] programı.

Figure 6. Lysimeter [PRG] program.

Lizimetre [PRG] programının hazırlanmasında "CASE" deyimi kullanılmıştır. $\mathrm{Bu}$ deyimin "iì" adım değişkeni 0-50 arasında değişmiştir. İlk adımda (ii $=0$ ), ölçme işleminin başlatılacağı saat "trg.1" değişkeni ile tanımlanmıştır. "trg.1" tetikleyicisi çıkış verdiğinde $(\mathrm{Q}=>)$, yani saat 10.00 olduğunda $(\mathrm{CLK}:=$ (saat.HOUR_ACT $=10$ AND saat.MIN_ACT $=0$ AND saat.SEC_ACT=0) "ii" adım değişkenine 10 atanarak ölçme işlemi (olcum:=TRUE) başlatılmıştır. Ölçme işleminin birinci gününde gün (i) değişkenine 1 değeri atanmıştır. Birinci günün tarihi (saat.day_act) "DATA[i].gun” dizisine, lizimetre tank1 ağırlığı (LZM_agirlik) ise "DATA[i].g_LZM_Ag" isimli diziye atanmıştır. Birinci gün; günlük evapotranspirasyon miktarına (DATA[i].g_ET:=0), drenaj miktarına (DATA[i].g_drenaj:=0), sulama miktarına (DATA $[\mathrm{i}] . \mathrm{slm} \_$mkt:=0), yağış miktarına 
(DATA[i].g_yagis:=0) ve toplam evapotranspirasyon miktarına (DATA[i].Top_ET:=0) sıfır değeri atanmıştır. Gün (i) değişkeni 1 artırılarak $(\mathrm{i}:=\mathrm{i}+1)$ ölçüm sonlandırılmış (olçum:=FALSE) ve dizilere atanan tüm değişkenler (DATA) SD karta kaydedilerek (veri_kayıt:=TRUE) ölçme işlemi tekrar $\quad \mathrm{ii}=0$ adımına yönlendirilmiştir. İkinci gün ve daha sonraki günlerde ( $\mathrm{i}>=2)$ "trg.1" tetikleyici değişkeni çıkış verdiğinde, yani saat 10.00 olduğunda ölçüm yapılan günün tarihi (saat.day_act) ve lizimetre ağırlı̆̆ı (LZM_agirlik) sirasıyla "DATA[i].gun" ve "DATA[i].g_LZM_Ag" dizilerine atanarak, adım değişkeni günlük yağış miktarının (g_yagis) belirlendiği ii= 20 adımına yönlendirilmiştir.

Günlük yağış miktarını (g_yagis) ölçmek için, birinci gün saat 10.00 'dan ikinci gün saat 10.00 'a kadar devrilen kovalı plüviyometrede yağış ile dolup boşalan kova sayısı belirlenmiştir (yagis). Kova sayısı (yagis) kova hacmi (Birim_Hacim) ile çarpılmış ve elde edilen sonuç plüviyometre yüzey alanına (Pluviyometre_alani) bölünerek "g_yagis" miktarı belirlenmiştir. "g_yagis" miktarının sıfırdan büyük olması durumunda, hesaplanan yağış miktarı "data[i].g_yagis" dizisine atanmıştır. Yağış gerçekleşmemesi durumunda ise diziye "g yagis" miktarı olarak sıfır değeri atanmıștır (data[i].g_yagis: $=0$ ). Ölçülen değer sıfirlanarak (g_yagis: $=0$ ), adım değişkeni günlük drenaj miktarının ( $g$ _drenaj) belirlendiği $\mathrm{ii}=30$ adımına yönlendirilmiştir.

Lizimetre tankından süzülerek, plüviyometreye aktarılan drenaj suyu ile dolup boşalan kova sayısı (drenaj) kova hacmi (Birim_Hacim) ile çarpılmış ve elde edilen sonuç lizimetre tankı yüzey alanına (LZM_tank_alani) bölünerek günlük drenaj miktarı (g_drenaj) hesaplanmıştır. "g_drenaj" miktarının sıfirdan büyük olması durumunda, drenaj miktarı "data[i].g_drenaj" dizisine atanmıştır. Drenaj gerçekleşmediğinde ise "g_drenaj" miktarı olarak diziye sıfır değeri atanmıştır (data[i].g_drenaj:=0). Günlük drenaj ölçümü sonunda ölçülen değer sıfirlanarak (g_drenaj:=0), adım değişkeni günlük evapotranspirasyon miktarının (gun_ET) belirlendiği ii $=40$ adımına yönlendirilmiştir.

"gun_ET" miktarının belirlendiği ii= 40 adımında, Lizimetre (PRG) programı bir boyutlu su dengesi eşitliğini kullanarak "gun_ET" miktarını hesaplamıştır. "gun_ET" miktarı sıfirdan büyük ise, hesaplanan "gun ET" değeri "data[i].gun_ET" dizisine atanmıştır. Evapotranspirasyon gerçekleşmemesi durumunda ise "gun_ET" miktarı olarak diziye sıfır değeri atanmıştır (data[i].g_ET:=0). Çalışma boyunca her gün için ayrı ayrı belirlenen "gun_ET" miktarları 15 günlük veri depolama kapasitesine sahip $^{-}(\mathrm{m}=1,15,1)$ "data[m].gun_ET" isimli geçici dizide depolanmıştır $(\mathrm{m}:=\mathrm{m}+1)$. $\mathrm{Bu}$ amaçla gün "i" değişkenine " $\mathrm{m}$ " değişkeni atanmıştır. "data[m].gun_ET" geçici dizisinde depolanan "gun_ET" miktarları yığışımlı olarak toplanmış ve bir sulama döngüsünde gerçekleşen "t_ET" miktarı belirlenmiştir. "t_ET" değeri "data[i].Top_ET" dizisine atanarak, sulama için karar verme adımına (ii $=50$ ) geçilmiştir.

Sulama için karar verme adımında (ii= 50), t_ET $<20 \mathrm{~mm}$ ise 0 ana kadar ölçülen veriler kaydedilmiş (veri_kayıt:=TRUE), ölçme işlemi sonlandırılmış (olçum:=FALSE) ve gün (i) değişkeni bir artırılarak $(\mathrm{i}:=\mathrm{i}+1)$ ölçme işlemi bir sonraki gün için tekrar ii= 0 adımına yönlendirilmiștir. $\mathrm{t}$ ET $>=20 \mathrm{~mm}$ olması durumunda ise sulama yapılmıştır. "Slm_mkt" hesaplanarak (Slm_mkt:=1.2*t_ET) "data[i].Slm_mkt" dizisine atanmıştır. Selenoid vana açılarak (valf:=TRUE) sulama başlatılmıştır. Lizimetre [PRG] programı tarafından açılan selenoid vana, sulama işleminin sonunda
Sulama [PRG] programı tarafinda kapatılmıştır. Sulama işleminin sonunda tüm değişkenler sıfirlanmış, ölçme işlemi sonlandırılmış (olçum:=FALSE) ve gün (i) değişkeni bir artırılarak $(\mathrm{i}:=\mathrm{i}+1)$ ölçme işlemi bir sonraki gün için tekrar $\mathrm{ii}=0$ adımına yönlendirilmiştir.

Tartılı lizimetre sistemine giren günlük yağış ( $\mathrm{g}$ yagis) miktarı ile tanktan çıkan günlük drenaj (g_drenaj) miktarını ölçmek ve sulama sistemini kontrol etmek amaciyla Şekil 7'de verilen yagis_olc [PRG], drenaj_olc [PRG] ve Sulama [PRG] programları hazırlanmıştır. Plüviyometreler çıkış verdiğinde (Pluviyometre, $\mathrm{Q}=>$ ), yani su ile dolan ilk kova boşaldığında "g_yagis" ve "g_drenaj" miktarlarının ölçülmesine başlanılmıştır. "F_TRIG_1" komutunun tetiklediği "yagis" sayacına yağışla dolup boşalan kova sayısı (yagis), "F_TRIG_2" komutunun tetiklediği "drenaj" sayacına ise drenaj suyu ile dolup boşalan kova sayısı (drenaj) saydırılmıştır. Lizimetre [PRG] programı sirasiyla, yagis_olc [PRG] ve drenaj_olc [PRG] programlarından saydırılan toplam kova sayılarını (yagis, drenaj) çekerek "g_yagis" ve "g_drenaj" miktarlarını belirlemiştir.

Lizimetre [PRG] programının selenoid vanayı açmasıyla birlikte dijital su sayacından su akımı geçmeye başlamıştır. Sulama [PRG] programı tarafindan kontrol edilen dijital sayaçtan her 1 litre su geçişinde 1 çıkış üretilmiştir. "F_TRIG_Sulama" komutunun tetiklediği "su_say" (su_say:=su_say+1) sayacı ile çıkış sayısı saydırılmıştır. Su sayacından geçirilen su miktarı (su_say) sulama suyu miktarına (Slm mkt) eşit olduğunda (su say $>=$ Slm mkt), selenoid vana Sulama [PRG] programı tarafindan kapatilarak (valf:=FALSE) sulama sonlandırılmıştır.

Lizimetre $[\mathrm{PRG}]$ programı tarafindan DATA dizinlerine kaydedilen bir önceki ve bir sonraki günün lizimetre ağırlıkları, bu iki lizimetre ağırlığı ölçümü arasındaki bir günlük sürede gerçekleşen yağış ve drenaj miktarları ile sulama suyu miktarı ve bu değerlere bağlı olarak hesaplanan günlük ve toplam evapotranspirasyon miktarları sd_kart_veri_yaz [PRG] programı tarafından SD karta yazdırmıştır.

PLC kontrollü tartılı lizimetre sistemi 2 yaşındaki Maraş 18 tipi ceviz bitkisi üzerinde test edilerek, bu sistem ile 2018 yılının Haziran-Ekim dönemi boyunca ölçülen yağış, drenaj, evapotranspirasyon ve sulama suyu miktarları Çizelge 1'de verilmiştir.

Maraş 18 tipi cevizin günlük evapotranspirasyon miktarı 1.25-3.5 mm gün ${ }^{-1}$ arasında değişmiştir. Sulama aralığı 6-16 gün arasında değişmekte olup, toplam 12 defa sulama yapılmıştır. Ceviz bitkisine günlük ortalama $2.50 \mathrm{~mm}$ sulama suyu verilmiştir. Sulama mevsimi süresince gerçekleşen toplam evapotranspirasyon miktarı $261 \mathrm{~mm}$ olup, ceviz bitkisine bu süre boyunca toplam $293 \mathrm{~mm}$ sulama suyu verilmiştir. Akın (2016), Chandler tipi ceviz bitkisinin Tekirdağ koşullarında evapotranspirasyon miktarını belirlemek amacıyla yaptığ çalışmada, Haziran-Eylül dönemi boyunca günlük evapotranspirasyon miktarının 2.23-5.43 mm gün ${ }^{-1}$ arasında değiştiğini belirlemiştir. Hu ve ark. (2010), ceviz ağaçlarının günlük ortalama evapotranspirasyon miktarlarının çiçeklenme aşamasında $2.90 \mathrm{~mm}$ gün ${ }^{-1}$, meyve oluşumu aşamasında 3.97 mm gün ${ }^{-1}$, kabuk oluşumu aşamasında $5.55 \mathrm{~mm}$ gün $^{-1}$ ve meyve olgunluk aşamasında $3.39 \mathrm{~mm} \mathrm{gün}^{-1}$ düzeyinde olduğunu belirtmişlerdir. $\mathrm{Bu}$ çalışma kapsamında Maraş 18 tipi ceviz bitkisi için elde edilen evapotranspirasyon değerleri, genel olarak Akın (2016) ve Hu ve ark. (2010) tarafından belirtilen değerler ile paralellik göstermektedir. 

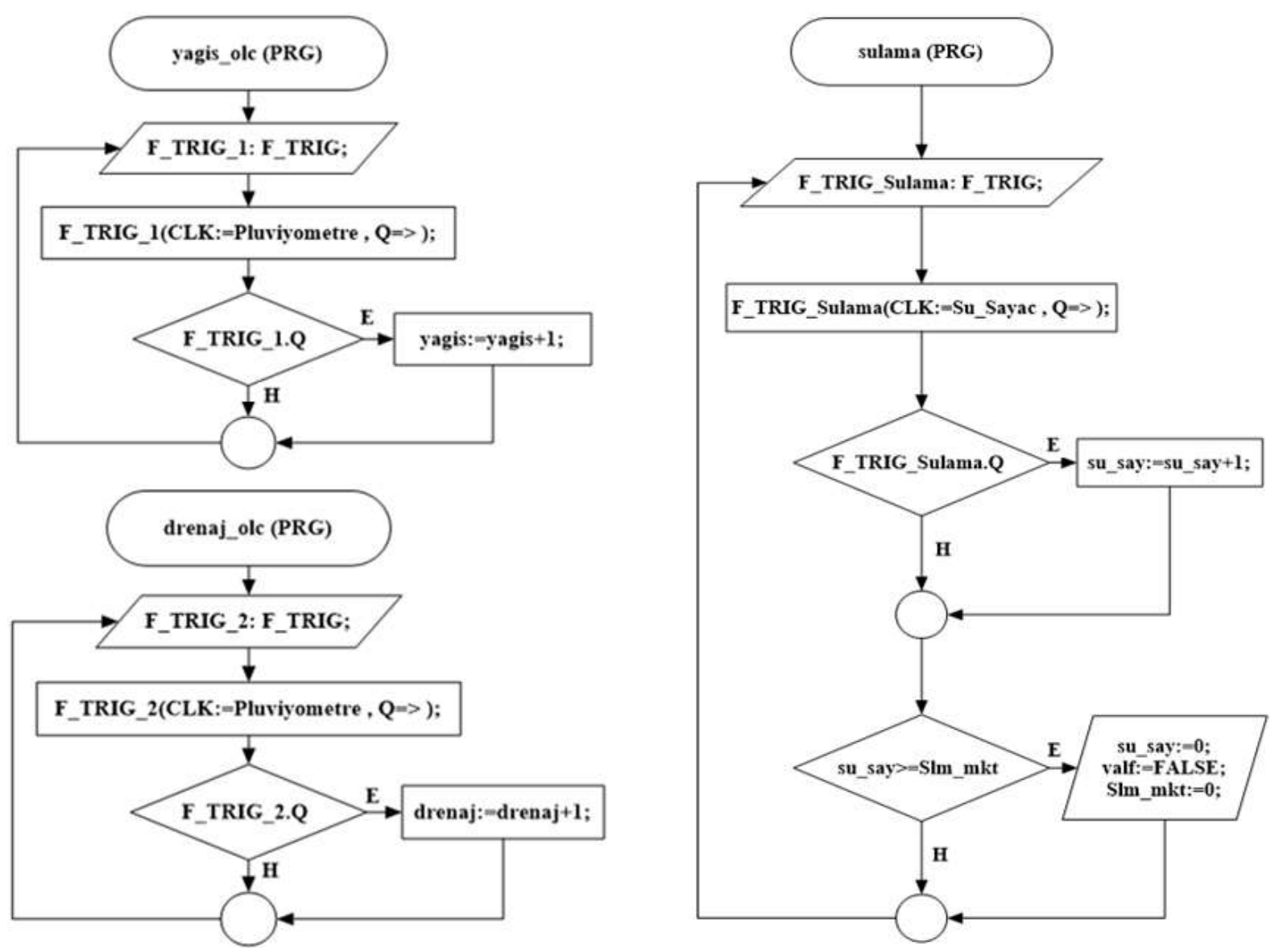

Şekil 7. yagis_olc [PRG], drenaj_olc [PRG] ve Sulama [PRG] programları.

Figure 7. yagis_olc [PRG], drenaj_olc [PRG] and Sulama [PRG] programs.

Çizelge 1. LZM_1, LZM_2, yağış, drenaj, sulama ve evapotranspirasyon miktarları.

Table 1. LZM_1, LZM_2, precipitation, drainage, irrigation and evapotranspiration amounts.

\begin{tabular}{cccccccc}
\hline \multirow{2}{*}{ Tarih } & \multirow{2}{*}{ LZM_1 (kg) } & \multirow{2}{*}{ Yağı̧ $(\mathrm{mm})$} & \multirow{2}{*}{ Drenaj $(\mathrm{mm})$} & \multirow{2}{*}{ Sulama $(\mathrm{mm})$} & \multicolumn{2}{c}{ Evapotranspirasyon $(\mathrm{mm})$} & \multirow{2}{*}{ LZM_2 (kg) } \\
\hline 15-26 Haziran & 2237.40 & - & - & - & 21 & 1.91 & 2216.40 \\
26 Haziran-3 Temmuz & 2216.40 & 9 & 8 & 25 & 20 & 2.86 & 2222.40 \\
3-9 Temmuz & 2222.40 & 5 & 7 & 24 & 21 & 3.50 & 2223.40 \\
9-17 Temmuz & 2223.40 & - & 6 & 25 & 21 & 2.63 & 2221.40 \\
17-24 Temmuz & 2221.40 & - & 4 & 25 & 20 & 2.86 & 2222.40 \\
24 Temmuz-1 Ağustos & 2222.40 & - & 5 & 24 & 20 & 2.50 & 2221.40 \\
1-8 Ağustos & 2221.40 & - & 4 & 24 & 20 & 2.86 & 2221.40 \\
8-21 Ağustos & 2221.40 & - & 6 & 24 & 20 & 1.54 & 2219.40 \\
21 Ağustos-2 Eylül & 2219.40 & - & 5 & 24 & 21 & 1.75 & 2217.40 \\
2-11 Eylül & 2217.40 & - & 6 & 25 & 21 & 2.33 & 2215.40 \\
11-18 Eylül & 2215.40 & - & 5 & 25 & 20 & 2.86 & 2215.40 \\
18 Eylül-4 Ekim & 2215.40 & 3 & 4 & 24 & 20 & 1.25 & 2218.40 \\
4-14 Ekim & 2218.40 & 2 & 6 & 24 & 16 & 1.60 & 2222.40 \\
\hline Toplam & 15 Haziran & 19 & 66 & 293 & 261 & - & 14 Ekim \\
\hline
\end{tabular}

LZM 1: Evapotranspirasyon miktarının belirlendiği dönemin başında ölçülen lizimetre ağırlığı.

LZM_2: Evapotranspirasyon miktarııı belirlendiği dönemin sonunda ölçülen lizimetre ağırlığı. 


\section{Sonuç}

$\mathrm{Bu}$ çalışma kapsamında PLC tabanlı otomasyon sistemi tarafindan kontrol edilebilen bir tartılı lizimetre sistemi geliştirilerek, Maraş 18 tipi ceviz bitkisi üzerinde test edilmiştir. Lizimetre sistemi günlük yağış ve drenaj miktarlarını plüviyometrelere, lizimetre ağırlıklarını ise elektronik kantara ölçtürerek kaydetmiştir. Bu verileri kullanarak cevizin günlük evapotranspirasyon miktarını, sulama suyu ihtiyacını ve sulama zamanını belirlemiştir. Sulamayı otomatik olarak başlatıp, suyun tamamı bitkiye verildiğinde sonlandırmıştır. Otomasyon kullanımı zaman ve iş gücünden tasarruf edilmesini sağlayarak, ölçme işlemlerinin hassasiyetini ve tutarlılığını artırmıştır.

Ceviz bitkisinin tart1l lizimetre sistemi ile elde edilen günlük evapotranspirasyon miktarları 1.25-3.5 mm gün ${ }^{-1}$ arasında değerler almıştır. 2018 yılı Haziran-Ekim dönemi boyunca gerçekleşen toplam evapotranspirasyon miktarı ise 261 $\mathrm{mm}$ olarak belirlenmiştir. Cevize günlük ortalama $2.50 \mathrm{~mm}$ sulama suyu verilmiştir.

\section{Kaynaklar}

ABB (2017) Automation Builder 2.1-Basic. ABB Automation Products GmbH Eppelheimer Str. 8269123 Heidelberg, Germany.

Aboukhaled A, Alfaro A, Smith M (1982) Lysimeters. FAO Irrigation and Drainage Paper No. 39, Rome.

Akın S (2016) Tekirdağ koşullarında ceviz ağaçlarının su tüketimlerinin belirlenmesi. Yüksek Lisans Tezi, Namık Kemal Üniversitesi Fen Bilimleri Enstitüsü, Tekirdağ.

Akpolat A (2011) Mikrometeorolojik ve lizimetre yöntemleriyle belirlenen buğday bitki su tüketimlerinin karşılaştırılması. Yüksek Lisans Tezi, Çukurova Üniversitesi Fen Bilimleri Enstitüsü, Adana.

Aydınşakir K, Baştuğ R, Büyüktaş D (2003) Antalya yöresinde çim kıyas bitki su tüketimini veren bazı ampirik eşitliklerin tarla ve lizimetre koşullarında kalibrasyonu. Akdeniz Üniversitesi Ziraat Fakültesi Dergisi 16(1): 107-119.
Aydınşakir K, Büyüktaş D (2014) Lizimetreler ve bitki su tüketimi çalışmalarında kullanımı. Batı Akdeniz Tarımsal Araştırma Enstitüsü DERIMM Dergisi 22(1): 49-58.

Benli B, Kodal S, İlbeyi AA, Üstün H (2006) Determination of evapotranspiration and basal crop coefficient of alfalfa with a weighing lysimeter. Agricultural Water Management 81: 358-370.

Doorenbos J, Pruitt WO (1977) Crop water requirements. FAO Irrigation and Drainage Paper No. 24, Rome.

Gençoğlan C, Gençoğlan S, Usta S (2019) Controlling lysimeter and lysimeter units with a Programmable Logic Controller (PLC). In: International Asian Congress on Contemporary Sciences. Mecca, Saudi Arabia, pp. 180-188.

Hu Q, Ma Y, He J, Zhang Q, Hong M (2010) Effect of drip irrigation and micro-sprinkler irrigation on water consumption, yields and quality of walnut. Journal of Water Resources and Water Engineering 1: 0-20.

Kanber R (2006) Sulama. Çukurova Üniversitesi Ziraat Fakültesi Ders Kitapları, Yayın No: A-52, Adana.

Nur A (2019) Çukurova koşullarında lizimetre yöntemiyle mısır bitki su tüketiminin ve bitki katsayılarının belirlenmesi. Yüksek Lisans Tezi, Çukurova Üniversitesi Fen Bilimleri Enstitüsü, Adana.

TAGEM (2016) Türkiye'de Sulanan Bitkilerin Bitki Su Tüketimi Rehberi. T.C. Gıda, Tarım ve Hayvancılık Bakanlığı Tarımsal Araştırmalar ve Politikalar Genel Müdürlüğü Yayınları, Ankara.

Ünlü M, Kanber R, Kapur B (2010) Comparison of soybean evapotranspirations measured by weighing lysimeter and Bowen ratioenergy balance methods. African Journal of Biotechnology 9(30): 4700-4713.

Yıldız AM (2019) Çukurova koşullarında lizimetre, eddy kovaryans ve su bütçesi yöntemleri ile belirlenen buğday bitki su tüketimlerinin karşılaştırılması. Yüksek Lisans Tezi, Çukurova Üniversitesi Fen Bilimleri Enstitüsü, Adana.

Young MH, Wierenga PJ, Mancino CF (1996) Large weighing lysimeters for water use and deep percolation studies. Soil Science 161: 491-501. 